\title{
Personal Development Planning: Addressing the skills gap for engineers in Oman
}

Tess Goodliffe

Caledonian College of Engineering, Muscat

\begin{abstract}
The aim of this paper is to discuss the decision made last year, by the Caledonian College of Engineering in Oman, to introduce compulsory modules in Personal Development Planning (PDP) at each level of study in the UK-awarded diploma and degree programmes. The primary objective of PDP is to improve the capacity of individuals to understand what and how they are learning, and to review, plan and take responsibility for their own learning. This paper describes how the main topic areas covered in PDP have been introduced to Omani engineering students; the learning/teaching methodology; how these modules are assessed and evaluated and how these areas relate to the needs of current and future employers. The challenges that have been faced during the implementation of these modules in terms of contextualisation (UK modules imported into an Omani environment) and external assessment are also discussed.
\end{abstract}

\section{Introduction}

The importance of preparing students for their future working environment has been a key issue in both higher and vocational education throughout the Gulf States. This paper will briefly provide a historical context of educational development in Oman before discussing the implementation of Personal Development Planning (PDP) modules at the Caledonian College of Engineering, a private university college in Oman. There follows an outline of the module contents, the learning and teaching methodology and assessment, and an analysis of the challenges faced when importing 'soft skill' modules designed for a UK-teaching context.

\section{Background}

Oman is the oldest independent state in the Gulf region, founded in 1650. The current head of state, H.M. Sultan Qaboos bin Said, came to power in 1970, in a country which up until his rule had been resistant to modernisation, and had had little investment in infrastructure. This historical perspective has implications for the scope of this paper as firstly, the implementation of national education and training policies has been a relatively recent 
development and secondly, the rapid construction of an Omani infrastructure has meant dependence on an imported labour force. To give an indication of the rate of development, at the time of Sultan Qaboos' accession thirty-four years ago, there were two schools in the Sultanate compared to currently 1019 schools, one national university (founded in 1985), 5 higher colleges of technology, 19 institutes/teacher training colleges, 14 private colleges and one private university.

The challenge currently facing Oman is the development of a competent and effective Omani workforce, with limited dependence on expatriate expertise. In 1995 'Vision 2020 for Oman's Economy' was launched, with a key focus on two areas: economic diversification in order to reduce oil's domination of the economy (so that it accounts for less than $20 \%$ of GDP by 2020); and the policy of 'Omanisation', the replacement of migrant workers with Omani nationals, which will underpin education, training and employment polices and practice:

"The Vision for human resources involves: creation of well-developed Omani human resources with capacities and skills that conform with the technical and technological development and characterized by high efficiency for management of changes" (Ministry of National Economy, 2002).

According to the 2003 census carried out in December 2003, of the current 2,331,391 population, 1,779,318 are Omani nationals and 552,073 expatriates. However, to put these figures into perspective, it has been estimated that more than $43 \%$ of the total Omani population is below the age of fifteen, whereas the expatriate residents are almost all adult members of the workforce.

In the field of basic education, the Omani government has established a solid infrastructure. The education system has adequate capacity to accommodate all school-age children, and claims to provide universal access to basic education (Ministry of National Economy, 2002). However, in 1997/1998 over 35,000 primary school-age children (6 - 11 years) and over 51,000 basic school-age children ( $6-14$ years) were outside the formal education system. Based on figures of the population census in 1993, it was estimated that the illiterate population for 15 year-olds and above reached $41 \%$, decreasing to $32 \%$ of the population in 1996 (based on labour force survey).

In 1998, the 'Basic Education System' was introduced. The ten-year programme aims to teach communication and learning skills, critical thinking, science and modern technology alongside more traditional school subjects. English language teaching has been introduced from grade 1 (first year of primary). The main objective of this programme is to produce school leavers with sound numeracy and literacy skills as a basis for further education and vocational training (Ministry of National Economy, 2002). However, there is currently a lack of careers guidance to provide school leavers with information about further educational 
opportunities. Choices are often made based on family and cultural perceptions of secure career routes (e.g. government employment).

As there are few opportunities for young Omanis to enter the workplace without some form of tertiary education or training, the key challenge is to provide an adequate number of places for the growing number of school-leavers. In June 2003, there were 41,568 school leavers matriculating but only 2,400 places available at Sultan Qaboos University (the only government-funded university) with another 2,400 places available at 14 private licensed institutions (D'Souza and Kapur, 2003). According to government statistics, there were 1,976 students studying at vocational training centres in the academic year 2002/2003 and a total of 2,626 students studying at the five industrial technical colleges in the same year (Ministry of National Economy, 2003). There is no significant workplace-based apprenticeship system in Oman apart from in a few indigenous craft industries such as pottery and carpet weaving. The provision of post-compulsory education system in Oman could therefore be described as a 'schooling model' as there is currently little involvement from an apprenticeship or non-formal sector.

Private higher education institutions have been initially reliant on affiliations with overseas universities in order to ensure quality and standards. In 2003, the Sultanate of Oman developed through the Higher Education Council and the Accreditation Board: 'mechanisms to conduct the accreditation of all private higher education institutions...irrespective of the individual institution's affiliation.' (Mclntosh, 2004) This has implications for the scope of this paper as the Omani Framework for undergraduate awards lays an emphasis both on developing generic competences and ensuring that the programmes offered in the private sector reflect both the context and priorities of higher education in Oman.

\section{Context for Personal Development Planning (PDP)}

Caledonian College of Engineering, University College, Oman (CCEO) was founded in Oman in 1996. It is a private university college, run under the auspices of the Omani Ministry of Higher Education, and affiliated to Glasgow Caledonian University (GCU) in the U.K. CCEO currently offers diplomas, ordinary degrees and honours degrees in the fields of electronic, telecommunications and computer engineering; mechanical and industrial engineering; and civil engineering/built environment. All courses are delivered in English, and are recognised both in Oman and in the U.K., hence internationally.

When students join CCEO, they are given an in-house college entrance test in English, Maths and Science. Based on the outcome of this test, students achieving an equivalent of IELTS band 5.5. in the English component along with evidence of competency in Maths and Science, are enrolled directly onto the engineering programme; students not meeting this 
level are given an opportunity to address their areas of weakness by attending courses, for at least one semester, in the 'Foundation' programme.

In September 2003, an implementation programme began in order to offer core modules in personal development planning (PDP) to all engineering students studying at CCEO. This is in line with the forthcoming move in UK education to introduce Progress Files, along with transcripts and personal development planning, for all students in post-16 education from the academic year 2005/2006. These PDP modules were developed by colleagues at Glasgow Caledonian University in the UK to provide a core component for the recently introduced modular Caledonian degrees.

Personal development planning has been described by the UK Quality Assurance Agency for Higher Education (2000) as follows:

A structured and supported process undertaken by an individual to reflect upon their own learning, performance and/or achievement and to plan for their personal, educational and career development.

It is believed that the skills acquired through PDP will enable students to be more effective in the workplace in response to the needs of Omani employers. Engineering students will benefit from having a greater awareness of themselves as learners, by being more confident communicators and by adopting a more pro-active approach in their studies and extracurricular life. This means that newly-qualified engineers will be ready for the workplace not only in terms of subject knowledge but also equipped with key life skills to enhance their employability. These skills are important beyond the shores of Oman; they are becoming an integral part of what global professional engineering bodies value in engineers. The context of these skills must therefore be national, regional and global.

\section{PDP core modules}

PDP is offered as a 20 -credit module out of a total of 120 credits at each level of study. The main areas covered in the modules are:

\section{PDP Module 1:}

The nature of higher education; personal development planning; reflective practice; critical thinking skills; learning strategies; core communication skills

Students are encouraged to reflect on the differences between the demands of school education (rote learning, teacher dependent, exam-focused) and the expectations of higher education. A number of questionnaires and tasks are used to develop an understanding of how individuals learn and how to optimise learning skills. There is a strong emphasis on academic writing skills, note-taking, research strategies and taking responsibility for one's 
own learning. Local professionals from engineering fields are invited to give presentations to the students on what they expect graduates to bring to the workplace, thus promoting the validity of PDP for engineers of the future.

\section{PDP Module 2:}

Theories of learning; the role of the organisation; organisational behaviour; understanding human personality; research strategies; problem-solving

The focus of this module is on encouraging students to have a greater awareness of how individuals work and interact in the workplace, as well as developing an understanding of how organisations are run. There is also an opportunity to explore different cultural working environments and the implications for workplace practice. Although problem-solving has been touched on in earlier modules in level 1, both in PDP and other engineering disciplines, there is a greater stress on the cognitive skills involved and problem-solving as part of a collaborative process.

\section{PDP Module 3:}

Researching the labour market; the value of networking; case studies of local issues; analysing success and personal goals; professional c.v. writing; interview techniques and preparation

This module provides an opportunity to contextualise the above content areas and look at the nature of employment in Oman. Students are expected to show an understanding of the recruitment process in different organisations, the types of opportunities available for engineers and the breadth of skills employers are looking for. A realistic self-appraisal of strengths and weaknesses is encouraged and assessed through critical incident analysis and reflective logs.

\section{PDP Module 4:}

Ethics and professional practice; entrepreneurship; leadership skills and development; emotional intelligence; team-building and collaborative skills

The idea behind this module is to groom engineers for future roles, not only as team members and work colleagues, but also as managers and leaders, in keeping with the spirit of Omanisation. Students are expected to carry out an in-depth study on essential life skills and to look into the framework for continuous professional development within the Omani public and private sectors, in the rapidly changing world of globalisation.

\section{Learning and teaching methodology}

The majority of students in Oman come to higher education with a background of teachercentred instruction and skills in rote learning. One of the roles of PDP is to encourage the 
spirit of the independent learner and to create a less teacher-dependent culture. Students are invited to develop an awareness of themselves as learners, to think about their learning preferences and learner styles, thereby gaining a better understanding of themselves and how they 'tick'. Workshops are delivered in preference to lectures, with an emphasis on task-based learning and problem-solving from early stages. Collaboration and group work are key features of the learning methodology, with a focus on the process of learning as opposed to an overemphasis on the product. However, the responsibility for creating independent learners spreads beyond the boundary of one module and depends on the flexibility of teaching staff in all departments.

Teaching style should be governed not by subject matter but by the balance between teacher directiveness and student control, usually set by the student's ability to participate as a self-directed, self-motivated, responsible learner (Grow, 1996)

Developing students as self-directed, motivated and responsible learners has repercussions beyond their time at CCEO. One of the aims of PDP is to produce qualified and competent engineers who have an awareness of the importance of continuous professional/personal development and have a good grounding in lifelong learning skills.

\section{Assessment and evaluation of PDP}

PDP modules are continuously assessed by formative assessments, presentations, personal development plans, reflective logs and critical incident analysis, case studies and project work. In module 3 students are expected to produce a CV to a professional standard and include an outline of the key skills relevant to their particular field of engineering. In module 4 students are encouraged to show their research on life skills through a video, web-site and by delivering a training session to their peers. All these approaches are a new challenge to the students' idea of assessment and evaluation as there are no formal examinations. Peer assessment is also included in order to encourage students to analyse each other's work and to stimulate critical reflection. Students are encouraged to take advice from peers rather than from tutors, and learners develop an ability to critically appraise other's work from a tutor's perspective. One of the goals of assessment is to give students tasks which have some relevance outside the classroom and relate to their future needs as engineers. The tasks can also be included in their Progress Files which can be offered to future employers as evidence of workplace skills development.

\section{Challenges facing the implementation of PDP}

There have been and still are a number of challenges facing the implementation of the PDP modules, which include: importing modules designed for a different culture; the level of 
English language skills required; research methods; assessment methods and encouraging engineering students to see the relevance of what they perceive to be superfluous 'soft skills'. There has even been a degree of resistance from teaching colleagues working in engineering departments who initially perceived PDP modules as unnecessary 'usurpers', taking up timetable space which could be used for more important technical-based subjects.

\section{Importing UK-developed modules}

As noted previously, the PDP modules initially introduced into Oman were developed by module leaders at Glasgow Caledonian University (GCU) as part of the 'Caledonian Degree' framework. This degree framework was introduced in 2002 with a view to reducing the number of students prematurely leaving their degree programmes. Students are able to 'pick and mix' modules so as to obtain the number of credit points in order to be awarded a 'generic' UK degree. The PDP module at each level acts as a kind of 'linchpin' and is therefore focused on ensuring that students have a sense of purpose and direction within a degree framework which has no specific subject area. These students may have motivational issues and may be undecided about their future professional choices; therefore there is an emphasis on self-analysis and goal-setting. In the context of CCEO, however, students are already focused on their future career path in an engineering field. This has implications for contextualisation as assignments have to be tailored to the needs of engineers, rather than a general student population, but still need to address the same learning outcomes.

The modules have been designed to include a significant amount of tutor support and consultation. In Glasgow, students have three-hour workshops once a week and are encouraged to negotiate deadlines and assignment topics. The number of students taking PDP modules within the Caledonian Degree framework in Glasgow varies between $10-30$ students (as of 2002/2003 statistics). At CCEO in 2003/2004 there were 198 students enrolled in PDP1 and 10 students enrolled in PDP3 and PDP4. In September 2004, 252 students enrolled in PDP1 and 123 students enrolled in PDP3. The analogy for this would be moving from a cottage industry to mass production. In order to compensate for this, students in Oman are given $4-6$ hours of tuition a week (with class sizes averaging $25-30$ ) with extra academic support through 'surgery times' with module tutors., bearing in mind that our students are studying these diploma and degree programmes in a foreign language. For 2004/2005 a comprehensive workbook has been produced by the PDP teaching team in Oman in order to give students extra guidance for assignments and self-study materials.

As UK-based modules, there are basic assumptions about the students' learning environment, study strategies and behaviour. Materials and topics relate to students who have been through the UK education system, are beginning to establish their 
independence and are facing a very different university experience to those students in Oman. The majority of students here live at home or in hostels and are sponsored either by their parents or are on Ministry scholarships. Unlike in the UK, attendance is monitored closely and there are limited opportunities for extra-curricular activities. These different learning environments have a significant impact on the quality of the assignments produced by students. In PDP1, students are asked to produce a reflective log based on experiential learning incidents. From the perspective of engineering students in Oman, their learning has been both teacher-focused and classroom-based, and they find it difficult to value other learning incidents that have taken place (i.e. events that shape students' behaviour or attitudes). Female students have relatively sheltered lives and have resorted to inventing learning incidents in order to satisfy the minimum number of reflective logs to be submitted. This has stimulated a rethink of the type of assessed reflective tasks that should be included in the syllabus for Omani learners.

The tutor/student power relationship is significantly different in the UK compared to in Oman, a cultural dimension highlighted by the social psychologist Geert Hofstede based on his extensive studies on national culture differences (Hofstede, 1980). According to Hofstede, in the Gulf States there is a large 'power distance' (the extent to which individuals perceive the importance of those in positions of authority), scoring 80 (on a scale of $1-100$ ) compared to the power distance in the UK of 35. Students in Oman will rarely contest a tutor's point of view, find it hard to negotiate deadlines and take initiative without the guidance and authority of the tutor.

\section{English language skills}

Students enrolling on CCEO degree programmes are enrolled as GCU students. At the end of their studies, students will be awarded the same UK qualification as their peers in Glasgow. The programmes and modules delivered at CCEO are designed or validated by engineering boards at GCU and assessed, internally and externally, to the same standards. There is no concession for students studying in a second language in Oman. For technical and science-based subjects the issue of language has not been seen as a serious barrier to students achieving success, apart from reports and extended project work (which have been highlighted by GCU external examiners). The arrival of a continuously assessed module that requires an ability to express ideas clearly in English has provided the greatest challenge, especially for engineering students who have deliberately avoided studies which are seen as 'liberal' or 'humanities-based'. The positive side of the coin, however, is that PDP has provided an opportunity for students to be credited for developing their 'communication skills'. 
One solution to tackle this problem has been to provide all PDP tutors with formal training in English language teaching methodology and approaches by running internationally recognised courses for staff. Assignment rubrics are broken down into 'manageable chunks', with clear specifications and transparent marking criteria. A glossary of key PDP terminology has been produced in English and Arabic and an Omani PDP tutor has been recruited and trained to provide further academic support, especially for level 1 students. Academic support sessions have been built into the teaching timetable and an intranet-based 'learning support' page has been developed with extracts from model assignments and links to useful web-sites.

\section{Research methods}

A key focus within PDP modules has been on how students can avoid plagiarism and how to use effective research and referencing strategies in written assignments. The problem of plagiarism, particularly with regard to web-based resources, is not unique to the Omani context. Plagiarism due to increased internet accessibility and advanced browsers has been reported on the increase in many universities. However, students in Oman currently have little awareness of the concept of ownership and perceive the internet as a legitimate source not requiring acknowledgement. Students at CCEO are subject to the same rules and regulations with regard to plagiarism as their peers in GCU, i.e. zero tolerance. A key component of PDP highlights the seriousness of submitting plagiarised work and provides support in both research methods and how to refer to sources within submitted work. There has also been an emphasis on: ensuring that all staff in all disciplines are dealing with plagiarism consistently; devising tasks which will make it harder to copy from other students and require original thinking; preparing drafts and outlines in class and looking at externally produced guidelines for good practice e.g. the UK-based JISC Plagiarism Advisory Service.

\section{Assessment}

As mentioned previously, PDP modules are continuously assessed and have no formal testing element. This has been treated with a certain degree of suspicion by students who are more comfortable with the 'face validity' of examinations. PDP learning outcomes require students to demonstrate the ability to reflect, show self-awareness and to plan ahead which would be difficult to assess under test conditions. From my experience in Oman, there is a perception amongst students that an assignment or exam grade is something bestowed by teachers and detached from the student's effort. A student with a complaint about a low grade is more likely to ask a tutor to 'help me, teacher' by increasing the grade for that assignment than asking what they need to do in order to be awarded a better grade in future. This has been a particular concern for level 1 students who have come from a school environment where it was possible to receive $80-90 \%$ for a piece of written work to a UK 
marking culture whereby $40 \%$ is a pass mark and a distinction is $70 \%$. In a subject area with no right/wrong answers, a great deal of time and effort has been spent on blind marking and benchmarking activities, ensuring that the marking criteria is transparent and consistently applied. Perceptions of good work however, can differ between PDP module leaders in the UK and module leaders in Oman. Although samples of GCU students' PDP assignments were brought to Oman for initial standardisation, the sheer volume and variety of work produced in Oman has inevitably given rise to differences of opinion. This has promoted the need to use both a GCU-based and a locally-based external assessor in order to maintain consistency and acknowledge the cultural context.

\section{Relevance to students}

Students are focused on receiving a diploma or degree at the end of their period of study how they get the piece of paper is not considered to be important. The issue of student motivation and lack of maturity towards their studies is pertinent amongst all disciplines. Students come from a background with limited focus on taking responsibility for their own learning. However, in the context of engineering studies at diploma and degree level, students also have problems relating the relevance of PDP to their field of study; PDP tutors themselves are concerned about the integration of PDP into other subject areas. The integration of PDP into engineering modules is an ongoing process. Initially, teaching staff across all disciplines at CCEO were given presentations on the introduction of PDP and its college-wide implications. Feedback so far has highlighted the importance of integrating the PDP modules and its role in providing support for students' work in their engineering-based modules. It is imperative that PDP is not perceived to be a stand alone subject out of touch with other disciplines. Embedding these new core modules calls for consultation and cooperation at every level. Elements of PDP can be introduced into other subject areas, e.g. encouraging reflection and action planning through assignment rubrics just as the needs of other disciplines can be brought into the syllabus of PDP, e.g. numeracy and statistics through surveys and case studies. Staff from all departments need to be convinced of the value of PDP in order to support its implementation within an engineering education environment.

There continues to be a healthy debate on the extent to which engineering education should be 'liberalised'. There is no doubt in engineering education circles that the core subjects key to an engineering education should not be diluted in order to make way for 'soft skills'. However, there is a clear responsibility to future employers in providing engineering graduates with 'employability skills', a notion endorsed in a 1996 report from the UK Committee of Vice-Chancellors and Principals: 
It is one of higher education's purposes to prepare students well for working life (CVCP, 1996)

In 1998 TMP Worldwide Research published the results of its survey which identified the key skills areas desired by employers in the UK. The most important of these included oral communication skills, team-working and listening. The incidence of these skills amongst graduates were seen by employers to be significantly below the level required (TMP, 1998). The development of these skills is not only within the domain of PDP modules, where achievement in these areas is measured through continuous assessment and evaluation. The importance of these skills can also be acknowledged when evaluating success in other traditional engineering-based disciplines. However, further research needs to be carried out in order to assess the needs of Omani employers to ensure that PDP modules being delivered to engineering students at CCEO are bridging the skills gap.

Graduate engineers being introduced into a rapidly changing world of technology need to leave university with a keen awareness that their education has not ended. The profile of education and training in Oman is 'front-loaded', with an emphasis on initial education and training. Apart from some organisations in the petroleum and telecommunications industries, there is limited government incentive for investment in upskilling, retraining employees or developing environments for lifelong learning. Through PDP modules, students are encouraged to take an active role in the learning process, thereby fostering independence and autonomy. By being aware of their own learning processes, students are in a position to appreciate a learning culture and the role that learning plays in their evolution as an engineer throughout their working life.

In order to ensure that the learning outcomes of PDP modules are relevant to Omani engineering students, it is imperative to contextualise imported modules from the UK and ensure their relevance for both the learning culture of the students as well as their future working environments, through consultation with engineering disciplines and Omani employers recruiting engineers. For employers, the aim is to produce engineers with effective workplace skills and an awareness of how their skills relate to employer interests. Through exposure to PDP, students will develop a solid grounding in lifelong learning skills and a commitment to continued personal development. At CCEO, our goal is to view engineering education from a holistic perspective - not only training engineers but also developing effective colleagues, managers and leaders, contributing to Oman's vision for the future. 


\section{Discussion/Reflection Questions:}

1. What provision is there in your context to support students developing these 'soft skills' of the kind discussed in this paper?

2. In your opinion, should the teaching of these 'soft skills' be covered in stand alone modules or should it be embedded in core subjects?

3. What can be done pre-tertiary level to prepare students for the workplace?

4. How can future employers be involved in developing the learning outcomes for 'soft skills' modules?

\section{About the Author}

Tess Goodliffe has been Head of the Educational and Personal Development at the Caledonian College of Engineering in Muscat Oman since 2003. She has been involved in education since 1987 and has worked in Turkey, Italy, France, Japan, Bahrain, Saudi Arabia and Oman. Her initial experience was in English language teaching and she has been involved with teacher training and teacher development since 1990 in both the private and public sectors. In 1996 she was a key figure in establishing the Middle East and North Africa Teacher Training Network. Tess worked for the British Council from 1996 to 2003 and ran teaching centre branches in Riyadh, Saudi Arabia and Muscat, Oman. This also provided an opportunity to train future managers and deliver management development courses, both locally, regionally and internationally. Her academic interests are in student motivation, nurturing talent, lifelong learning skills and continuous professional development for teaching staff.

\section{References}

Committee of Vice-Chancellors and Principals. (1996). DfEE Helping Students Towards Success at Work: An intent being fulfilled. Cited in Cottrell, S. (2001). Teaching Study Skills and Supporting Learning. Basingstoke: Palgrave Macmillan

Grow, G. (1991/1996). Teaching Learners to be Self-Directed. Adult Education Quarterly, 41 (3), 125-149.

Hofstede, G. (1980). Culture's Consequences. Beverly Hills; Sage.

Mclntosh, F. (2004). The national and international recognition of engineering degree programmes: developments in the Sultanate of Oman. In Congress Proceedings for $4^{\text {th }}$ Global Congress on Engineering Education, UICEE : Monash University Australia Ministry of National Economy. (2002). Sixth Five Year Development Plan 2001 - 2005: 
Human Resources Development. Volume 2. Ministry of National Economy, Oman.

Ministry of National Economy. (2003). Statistical Year Book, $31^{\text {st }}$ issue. Ministry of National Economy, Oman.

Quality Assurance Agency for Higher Education. (2000). http://www.qaa.ac.uk/Heprogressfile $(30 / 5 / 2000)$

TMP Worldwide Research. (1998). Soft skills: employers' desirability and actual incidence. Cited in Cottrell, S. (2001). Teaching Study Skills and Supporting Learning. Basingstoke: Palgrave Macmillan 